\title{
Environmental sustainability assessment of a biomass-based chemical industry in the Visegrad countries: Czech Republic, Hungary, Poland, and Slovakia
}

\author{
Edit Cséfalvay ${ }^{1}$ ] Tamás Hajas $^{1}$ - László T. Mika ${ }^{2}$
}

Received: 22 February 2020 / Accepted: 24 April 2020 / Published online: 12 May 2020

(c) The Author(s) 2020

\begin{abstract}
Three recently introduced ethanol equivalent-based sustainability metrics i.e., the sustainability value of resource replacement, the sustainability value of the fate of waste, and the sustainability indicator were used to assess the environmental sustainability of the possible bioethanol-based chemical industry in the Visegrad countries: Czech Republic, Hungary, Poland, and Slovakia. The production of basic chemicals such as ethylene, propylene, toluene, xylenes, styrene, and benzene from bioethanol was evaluated. The theory is based on the utilization of cornstarch-based, first-generation bioethanol as a feedstock to produce bio-ethylene, which could be subsequently used as a starting material of well-established chemical technologies to synthesize the listed bulk chemicals. The analysis, which is a non-life-cycle assessment-based approach enlightened that although the switch of the chemical industry from crude oil to bioethanol would be theoretically feasible, the actual bioethanol production was far less than required to cover the raw material needs. Due to the high conversion and selectivity of the reactions studied, the sustainability value of the fate of the waste approached the sustainable value in case of ethylene production (i.e., 1), and the sustainability value of resource replacement acted as the limiting factor in sustainability indicator calculation. We showed a possibility to replace fossil-fuel resources with bioethanol, though the actual bioethanol volumes are not enough to cover the resource needs. Of the Visegrad countries, Slovakia shows the highest sustainability, but none of them can reach the minimum sustainable value of 0.5 up to now.
\end{abstract}

Keywords Environmental sustainability index $\cdot$ Ethanol equivalent $\cdot$ Biomass-based chemical industry $\cdot$ Basic chemicals Visegrad countries

This work was presented at the 46th International Conference of Slovak Society of Chemical Engineering held in Tatranské Matliare on May 20-23, 2019.

Electronic supplementary material The online version of this article (https://doi.org/10.1007/s11696-020-01172-8) contains supplementary material, which is available to authorized users.

Edit Cséfalvay

csefalvay@mail.bme.hu

1 Department of Energy Engineering, Faculty of Mechanical Engineering, Budapest University of Technology and Economics, Múegyetem rkp. 3., Budapest 1111, Hungary

2 Department of Chemical and Environmental Process Engineering, Budapest University of Technology and Economics, Múegyetem rkp. 3., Budapest 1111, Hungary

\section{Introduction}

While the unpredictable date of depletion of currently utilized fossil resources has urged researchers and engineers to find and map the possible candidates for their replacement, there are still several open questions, for example, on the viability of these alternative supplies. Fossil resources act as primary energy resources as well as raw materials for the production of routinely used value-added chemicals. It has been clearly demonstrated that fossil energy cannot be replaced completely by renewables (Cséfalvay et al. 2015; Cséfalvay and Horváth 2018); however, the raw material replacement in the chemical industry seems to be a more realistic goal (Petersen 2004; Horváth et al. 2017) by the use of bioethanol. The intensive research activity on the applications of bio-based chemicals started ca five decades ago and the group of possible surrogates, which could be obtained via appropriate chemical conversion of biomass, 
were proposed (Petersen 2004). The successful production of chemicals on biomass basis at laboratory scale served as an economic driver to realize the production in a biorefinery at industrial scale; though the question is still how to be economic? Our recent review subjected to overview the conversion of biomass to initial platform chemicals (IPCs) i.e., ethanol, 3-hydroxypropionic acid, propionic acid, succinic acid, furfural, levulinic acid, isoprene, and 5-hydroxymethylfurfural (Scheme 1) focusing on industrial-scale realizations (Mika et al. 2018). It was concluded that the volume had to be considered as a crucial factor of this purpose. In addition, it should be noted that the first-generation bioethanol has been produced at a million tons scale exclusively as well as the production of the second-generation bioethanol (i.e., cellulosic-ethanol), and other chemicals has been demonstrated only at kilotons scale (Yang et al. 2017; Jansen and van Gulik 2014; Mamman et al. 2008; Nghiem et al. 2017; Convay 2020). The production of basic chemicals at a million tons scale on biomass basis could represent a breakthrough for this global challenge.

Second-generation biorefinery could also be a possible solution to replace fossil resources of the chemical industry. Biorefinery operates similarly to crude oil refineries: it utilizes every single carbon atom of the biomass constituents. If the biomass contains carbohydrates which could be easily withdrawn and further processed via simple fermentation to produce bioethanol, this bioethanol could serve as a raw material of the second generation biorefinery (Horváth et al. 2017).

The chemical dehydration of ethanol to ethylene was demonstrated in the 1950s. The reaction is endothermic represented by conversion of $100 \%$ and selectivity of $99 \%$. Ethylene can undergo several well-known reactions such as hydration, dimerization, hydroformylation, cyclization, addition, alkylation, oxidation or metathesis; therefore, the existing petrochemical technology can be used, and a brunch of bulk chemicals can be produced. In this manner, bio-based ethanol could replace the fossil-based raw materials of the chemical industry (Mika et al. 2018; Horváth et al. 2017). Horváth and co-workers mapped the possible reactions routes and showed how basic chemicals could be produced on bioethanol and bio-ethylene bases. The scheme of bioethanol-based chemical production is summarized in Fig. 1.

Once the production of bulk chemicals on a biomass basis is feasible, it worth assessing whether it is sustainable or not. Although the life cycle assessment (LCA) is a commonly utilized method to evaluate the environmental impacts of a bio-based production of a selected compound, for example, ethanol (Zhao et al. 2020; Guerrero and Muñoz 2018; Chang et al. 2017), LCA cannot reveal any intrinsic properties of sustainability by thermodynamic viewpoints. It has to be emphasized that ethanol equivalent-based environmental sustainability calculations, which stand on nature-defined two pillars: resource reproduction and waste decomposition (Cséfalvay et al. 2015) fundamentally differ from the LCA. The calculations are based exclusively on thermodynamic fundaments and technological data (conversion and selectivity of the corresponding process), which are independent of any ecological, social, and even economic viewpoints. Thus, the most "optimistic" approach of biomass-based production of selected compounds can be provided. If any additional issues i.e., transportation, pretreatment of raw material, separation, product formulation, transportation, etc. are considered, even worse picture can be depicted.

Both sustainability metrics for basic chemicals consumed in the USA for 2008 and 2014 (Horváth et al. 2017) and sustainability assessment of renewable energy in the USA, Canada, China, and the Russian Federation were published (Cséfalvay and Horváth 2018). While the USA as a member of G7 countries has high chemical industrial potential [Chemical sales 468 billion EUR in 2018 (CEFIC 2020)], high consumption rates of basic bulk chemicals, no sustainable analysis has been published for countries having smaller-scale chemical industries. Therefore, Czech Republic, Hungary, Poland, and Slovakia, so-called the Visegrad countries having old-established smaller-scale chemical industries were selected as representative for this purpose. Chemical sale in the USA and turnover values of chemical industry in Visegrad countries (CEFIC 2020), as well as

Scheme 1 Biomass-based initial platform chemicals

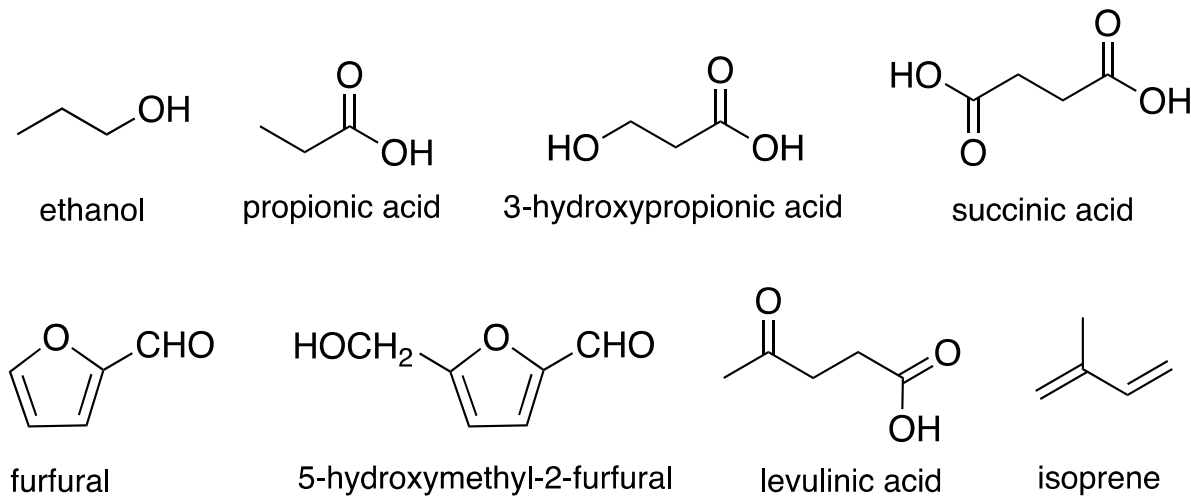




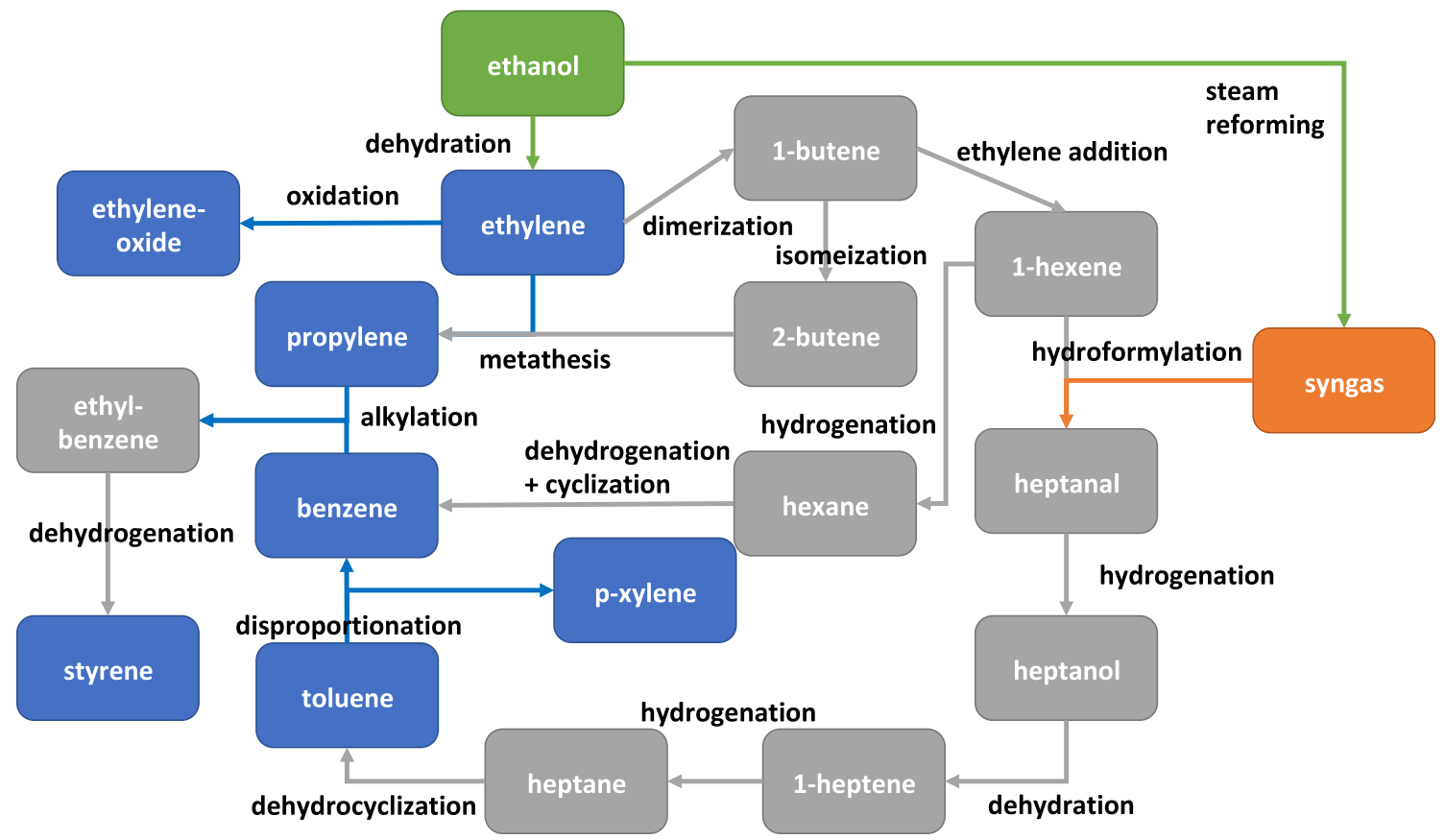

Fig. 1 Reaction routes of a bioethanol-based secondary biorefinery (chemicals in gray boxes show the intermediates, blue ones show the products evaluated in this study (except ethylene-oxide), orange represents syngas required for hydroformylation also produced on ethanol basis)

total and agricultural lands, which could be considered as a current maximum for corn production, are summarized in Table 1.

Herein, we report the environmental sustainability assessment of the biomass-based chemical industries in the Visegrad countries by using of sustainability indicator of ethylene, propylene, toluene, para-xylene, styrene, and benzene as main resources of current chemical processes. Although ethylene-oxide can be easily produced from ethylene via oxidation, its evaluation is not considered here, because it is not produced in the Visegrad countries.

\section{Methodology of environmental sustainability assessment}

Ethanol equivalent-based (Cséfalvay et al. 2015) sustainability metrics $\left(\mathrm{SV}_{\text {rep }}\right.$ and $\left.\mathrm{SV}_{\text {waste }}\right)$ were selected for the assessment. These metrics are the mathematical manifestation of the two pillars of alternative definition of sustainability: "the Earth's natural resources, including energy, should be used at a rate at which they can be replaced naturally" (envisioned in $\mathrm{SV}_{\text {rep }}$ ) "and the generation of waste cannot be faster than the rate of their remediation" (formulated in the equation of
Table 1 Turnover values of chemical industry and area data of the USA and Visegrad countries

\begin{tabular}{llcc}
\hline & $\begin{array}{l}\text { Turnover of chemical industry } \\
(2019, \text { billion EUR })\end{array}$ & Area $\left(1000 \mathrm{~km}^{2}\right)$ & $\begin{array}{c}\text { Agricul- } \\
\text { tural land } \\
\left(1000 \mathrm{~km}^{2}\right)\end{array}$ \\
\hline USA & $468^{\mathrm{a}}$ & 9834 & 40,586 \\
Czech Republic & $19.77^{\mathrm{b}}$ & 78.866 & 34.890 \\
Hungary & $5.4^{\mathrm{c}}$ & 93.030 & 52.830 \\
Poland & $62.15^{\mathrm{d}}$ & 312.679 & 143.740 \\
Slovakia & $10.34^{\mathrm{e}}$ & 49.035 & 18.860 \\
\hline
\end{tabular}

${ }^{\mathrm{a}}$ Chemical sale, turnover is not available for 2019

${ }^{\mathrm{b}}$ Soucek (2020)

${ }^{\mathrm{c} B u d a i}$ (2020)

${ }^{\mathrm{d}}$ Zielinski (2020)

${ }^{\mathrm{e}}$ Surova (2020) 
$\mathrm{SV}_{\text {waste }}$ ). Ethanol equivalent (EE) acts as a translational tool because it has dual advantages: (1) it represents a renewable carbon source and (2) it has a definite energy content that can be used to cover the reaction enthalpies. The kinetics of resource (i.e., material and energy) reproduction $\left(\mathrm{SV}_{\text {rep }}\right)$ was defined according to Eq. 1a (Horváth et al. 2017) and can be reformulated to gain two separate domains: the material + energy domain and the time domain (Eq. 1b). Although $\mathrm{SV}_{\text {rep }}$ is dimensionless, it should be emphasized that all the parameters have to be substituted as follows: million tons in case of EE, and year in case of time.

$\mathrm{SV}_{\text {rep }}=\frac{\frac{\frac{\mathrm{ERoE}}{1+\mathrm{ERoE}} \cdot \frac{\mathrm{ERoE}}{2.3} \cdot \mathrm{EE}_{\text {available resources }}+\mathrm{EE}_{\text {secondary resources }}}{\frac{t_{\text {replacement }}}{\mathrm{EE}_{\text {necessary resources }}}}}{t_{\text {consumption }}}$

$\mathrm{SV}_{\text {rep }}=\frac{\frac{\mathrm{ERoE}}{1+\mathrm{ERoE}} \cdot \frac{\mathrm{ERoE}}{2.3} \cdot \mathrm{EE}_{\text {available resources }}+\mathrm{EE}_{\text {secondary resources }}}{\mathrm{EE}_{\text {necessary resources }}} \cdot \frac{t_{\text {consumption }}}{t_{\text {replacement }}}$
ERoE represents the ethanol return on ethanol that reflects the efficiency of bioethanol production created as a sustainable approach of ERoI (Murphy and Hall 2010), when the input energy is covered from bioethanol. 2.3 represents the ERoE of the reference industrial-scale ethanol production technology practiced in 2008 in the USA (Shapouri et al. 2010). From 2016 on ERoE value of 4 could be applied due to the improved ethanol production technology (Gallagher et al. 2016). $E_{\text {available resource }}$ is the quantity of bioethanol produced in a given year, and $\mathrm{EE}_{\text {secondary resource }}$ means if a chemical is formed in another technology, it can be used as raw material, so the sustainability of resource reproduction could be increased. Certainly, it has to be expressed in EE to have combinable values. $\mathrm{EE}_{\text {necessary resource }}$ represents the material (including the gross yields of each reaction step) and energy (gross reaction enthalpies) requirements of the selected chemical on bioethanol basis. Time domain actually equals 1 , if 1 year is assessed for chemical consumption, and 1 year is calculated for first-generation bioethanol production under continental climate (corn planting, growing, harvesting, grain processing, fermentation, and purification of fermentation broth to reach bioethanol).

The second pillar of sustainability lays on the kinetics of waste formation and remediation. Its formulation can be achieved by the value of $\mathrm{SV}_{\text {waste, }}$, which was defined by Eq. 2 . The generated waste during production has to be expressed in EE as well, and it can be separated to treated or untreated waste. Because carbon-based chemicals are assessed, gaseous-phase waste can easily be purged and burnt immediately. If untreated, it is released to the environment and the longest natural decomposition time has to be accounted.
Natural decomposition times of the selected chemicals for each recipient (lake, river, air, and soil) were collected from (Pubchem 2020) and can be seen in supporting information. The two pillars $\left(\mathrm{SV}_{\text {rep }}\right.$ and $\left.\mathrm{SV}_{\text {waste }}\right)$ are combined into a single index according to Eq. 3 similarly to the equation used to calculate the resultant resistance of resistances connected parallel.

$\mathrm{SV}_{\text {waste }}=\frac{\frac{\mathrm{EE}_{\text {treated waste }}+\mathrm{EE}_{\text {untreated waste }}}{t_{\text {waste treatment }}+t_{\text {waste natural decomposition }}}}{\frac{\mathrm{EE}_{\text {generated waste }}}{t_{\text {waste generation }}}}$

$\mathrm{SUS}_{\text {ind }}=\frac{\mathrm{SV}_{\text {rep }} \cdot \mathrm{SV}_{\text {waste }}}{\mathrm{SV}_{\text {rep }}+\mathrm{SV}_{\text {waste }}}$

\section{Data used for assessment}

Group of four European countries Czech Republic, Hungary, Poland, and Slovakia are called as Visegrad countries or V4 countries. V4 countries have been selected for the sustainability assessment, since they are located close to each other in Europe, having similar geography and same continental climate, which proves the same conditions for corn production to provide bioethanol. Bioethanol production can vary from year to year according to actual sunshine hours, rainfall, soil cultivation, fertilizers, etc., and the annual bioethanol production data in million tons for each country are shown in Fig. 2.

To calculate $\mathrm{SV}_{\text {rep }}$ values, annual production data of each basic chemical were collected for all the countries studied, which are presented in Fig. 3. While ethylene and propylene production are dominant in Hungary and Poland, Czech Republic and Slovakia rather produced benzene and toluene. Meta-xylene's volume is also remarkable in Slovakia. Although ethyl-benzene, ethylene-oxide, and styrene have also been considered as basic chemicals, their production is insignificant in the selected countries; therefore, they are not included in this study.

\section{Results and discussion}

\section{Analysis of sustainability of resource reproduction}

When the production of these basic chemicals would be based on bioethanol, the limited amount of bioethanol has to be distributed proportionally for each chemical. This 


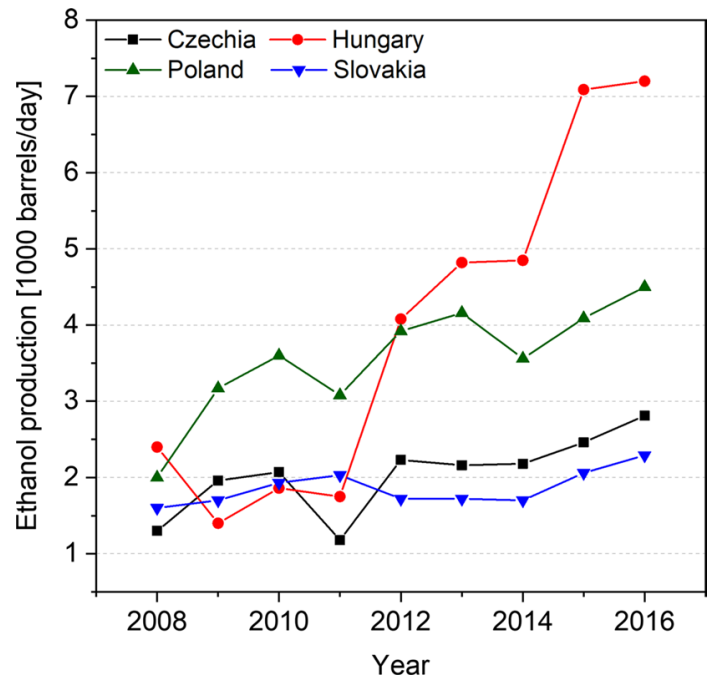

Fig. 2 Bioethanol production in Czech Republic (Knoema 2020a), Hungary (Knoema 2020b), Poland (Knoema 2020c), and Slovakia (Knoema 2020d)

approach has been used during the assessment of $\mathrm{SV}_{\text {rep }}$ in each country. The simplest representative of this approach is the $\mathrm{SV}_{\text {rep }}$ calculation in Czech Republic. 1.3 thousand barrel/ day bioethanol was produced in Czech Republic in 2008, i.e., 0.06 million tons were produced annually. This small amount of bioethanol has to be distributed between benzene and toluene, because only these two basic chemicals of the selected ones were produced in this country. Altogether, 0.71 million tons of ethanol would be needed to cover the production of toluene and benzene, which is 10 times more than the available bioethanol. Overviewing the available data between 2008 and 2012, it can be stated that the produced bioethanol is far below the amount would be needed resulting in $\mathrm{SV}_{\text {rep }}$ values lower than 0.12 (Fig. 4a). Even if the total bioethanol would have been used to produce one of the chemicals, the $\mathrm{SV}_{\text {rep }}$ value still remains far below the sustainable value $\left(\mathrm{SV}_{\text {rep }}=1\right)$.

Similar calculations were performed for Hungary, Poland, and Slovakia using the assumption of evenly distributed bioethanol as a resource. In case of Hungary (Fig. 4b), a significant difference can be seen between 2015 and 2016, which can be explained by the increase in the ERoE value: $\mathrm{ERoE}=2.3$ (Shapouri, et al. 2010) was used from 2008 to 2015 and $E R o E=4$ (Gallagher et al. 2016) from 2016 onward. Although the bioethanol production was also grown up to 7.2 from 7.09 thousand barrels/day, this increase alone cannot result in a doubled $\mathrm{SV}_{\text {rep }}$ value. The remarkable
Fig. 3 a Basic chemical production in Czech Republic between 2008 and 2012, b Hungary in 2015 and 2016, c Poland in 2009, 2010, 2015 and 2016, d Slovakia in 2015, 2016 and 2017 (Eurostat 2020)
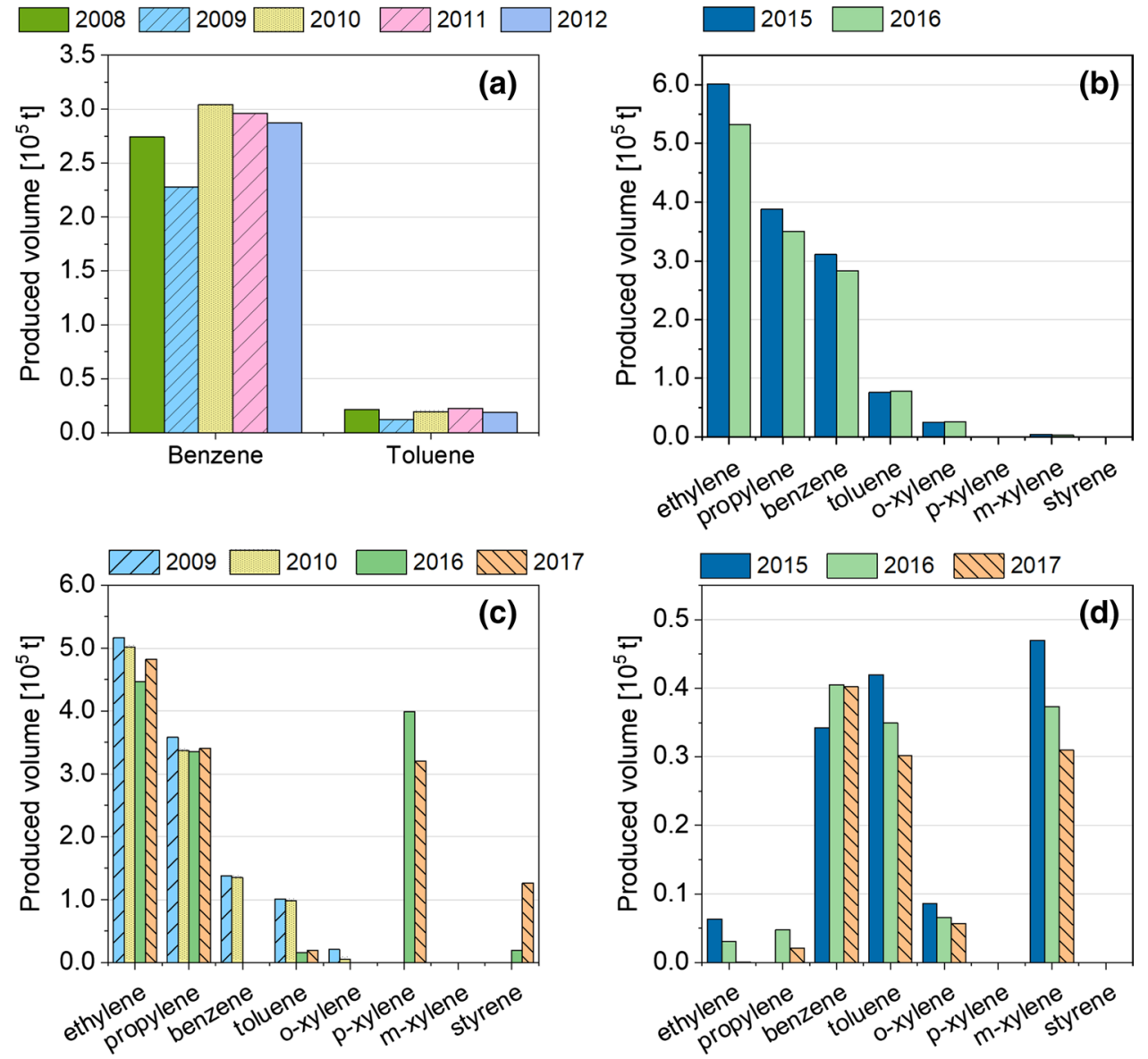
Fig. 4 Sustainability values of resource reproduction of basic chemicals in a Czech Republic, b Hungary, c Poland, d Slovakia
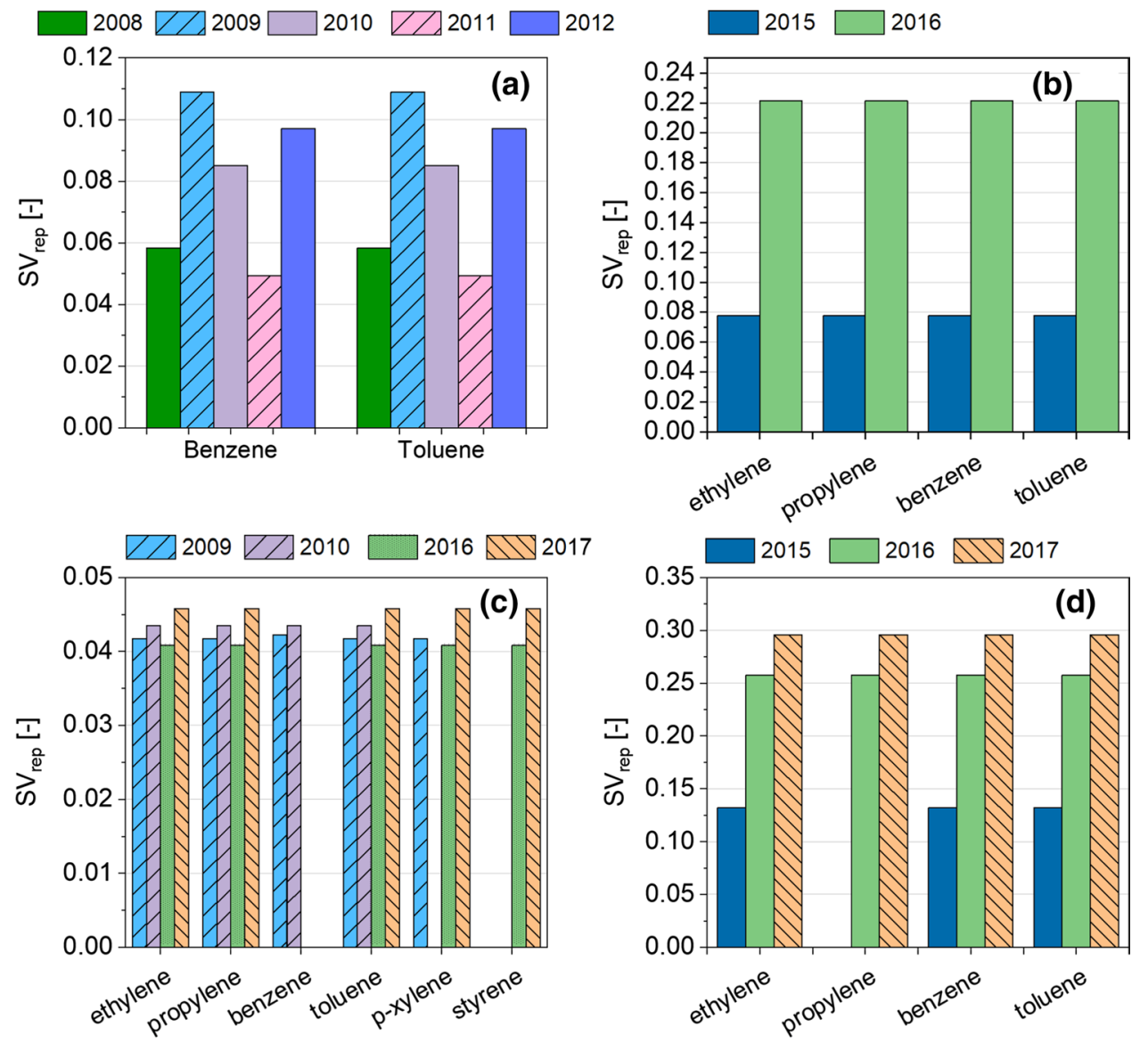

increase in ERoE was not conducted to significant growth of $\mathrm{SV}_{\text {rep }}$ in Poland. Because the chemical industry in Poland produces six different basic chemicals, and the bioethanol has to be distributed proportionally, $\mathrm{SV}_{\text {rep }}$ values show a moderate increase over the years (Fig. 4c). A significant increase in $\mathrm{SV}_{\text {rep }}$ can be seen in year 2016 in Slovakia (Fig. 4d) due to both the significant increase in the chemical industry and the ERoE value. When enough bioethanol would be available for the chemical reaction, moreover, the energy requirements could be covered from bioethanol as well, $\mathrm{SV}_{\text {rep }}$ value would reach one or increase beyond. As it can be seen in Fig. 4, $\mathrm{SV}_{\text {rep }}$ values remain below 0.3 in all cases, which is far away from the sustainable 1 and proves the scarce volume of existing bioethanol. It should be noted that the $\mathrm{SV}_{\text {rep }}$ value of ethylene, propylene, and toluene for the USA in 2014 did not exceed 0.2, which also proves the limited volume of bioethanol (Horváth et al. 2017).

\section{Analysis of sustainability of the fate of the waste}

$\mathrm{SV}_{\text {waste }}$ equals one when all the generated waste is treated during the chemical production and no wastes are released to the environment. Incineration, chemical and/or biological treatment, and disposal can be applied as treatment methods, and their time requirements have to be applied as treatment time. If no treatment is applied, then all wastes are released to the environment and must be considered as untreated waste, which possesses corresponding natural decomposition times. Because the generated waste during the production of the given chemical is either treated or untreated, every single atom is accounted for. When the EE of the waste is calculated, the situation is similar and mass balance can be expressed according to Eq. 4 .

$\mathrm{EE}_{\text {generated waste }}=\mathrm{EE}_{\text {treated waste }}+\mathrm{EE}_{\text {untreated waste }}$

Consequently, sustainability of the fate of the waste depends on exclusively on the waste treatment and waste natural decomposition times, so Eq. 2 can be simplified to formula of Eq. 5.

$\mathrm{SV}_{\text {waste }}=\frac{t_{\text {waste generation }}}{t_{\text {waste treatement }}+t_{\text {waste natural decomposition }}}$

Production and consumption data represent annual volumes, and waste is generated during the whole year, thus waste generation time must equal 1 year. Waste can be divided into two parts: treated or untreated and treatment methods could include incineration, chemical and/or biological treatment, 
and disposal. In the case of the selected chemicals treatment is narrowed to combustion, which is a prompt reaction and takes place immediately after purge. Therefore, waste treatment time equals 1 year. Although combustion does not require additional time, natural decomposition of chemical if released to the environment does. So, all the wastes have to be identified first, then their half-lives in the different environment have to be determined. The detailed chemical reactions from ethanol to the named chemicals including conversion, selectivity, and identified waste compounds are summarized in our previous work (Horváth et al. 2017). Wastes formed during each reaction step with corresponding natural decomposition times for ethylene, propylene, benzene, toluene, xylenes, and styrene are summarized in Supporting Information Table S1. When waste is released to the environment, natural decomposition occurs and the time requirement must include the generation time i.e., 1 year in our case. Additionally, the time needed to reach the local governments' regulation level in the environment based on its natural half-life. Applying the rule of thumb, concentration reduced to $0.1 \%$ of the initial concentration may have a negligible effect on the environment, so we calculated the time required to reach $0.1 \%$ of the annual volume of waste.

Multistep technologies are used during propylene, benzene, toluene, xylenes, and styrene production, and wastes are generated almost in each step. In these cases, the longest time of natural decomposition should be used for the overall process. To cover all occasions of contamination of air, water, or soil, the longest time of natural decomposition should be used (Table 2). When calculating $\mathrm{SV}_{\text {waste }}$ treated wastes have to be considered, which are incinerated immediately during the chemical production, therefore, 1 year of waste treatment is used in the calculations. Table 2 and Fig. 5 show that the chemical production technology governs the value of $\mathrm{SV}_{\text {waste }}$, which is close to sustainable in the case of ethylene production $\left(\mathrm{SV}_{\text {waste }}=0.957\right)$. Because the other basic chemicals can be produced via $3,4,7,8$, and 6 steps (propylene, benzene, toluene, xylenes, and styrene, respectively), and the conversion and or/selectivity of the reactions are lower than $100 \%$, wastes form that are either treated or untreated but worsen the overall $\mathrm{SV}_{\text {waste }}$ value.

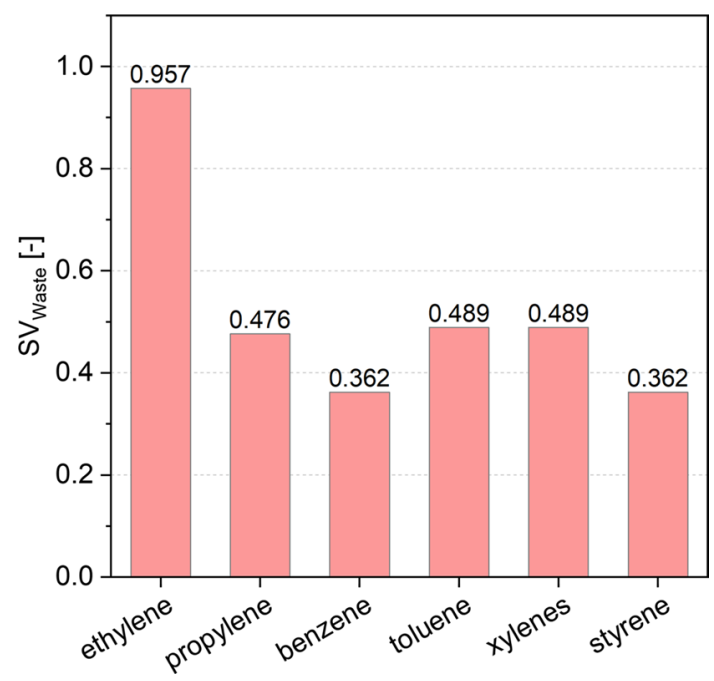

Fig. 5 Sustainability values of the fate of the waste for ethylene, propylene, benzene, toluene, xylenes, and styrene determined by the chemical technology

Table 2 Representatives of wastes formed during the production of basic chemicals: untreated wastes having the longest natural decomposition times and incinerated wastes

\begin{tabular}{|c|c|c|c|c|c|c|}
\hline Compound & $\begin{array}{l}\text { Untreated waste having the long- } \\
\text { est natural decomposition time }\end{array}$ & Released to & $\begin{array}{l}\text { Natural } \\
\text { decomposi- } \\
\text { tion time }\end{array}$ & $\begin{array}{l}\text { Time of natural } \\
\text { decomposition }^{\text {a }}\end{array}$ & Incinerated waste & $\begin{array}{l}\text { Time of } \\
\text { incineration } \\
\text { (year) }\end{array}$ \\
\hline Ethylene & $\begin{array}{l}\text { Oxygenates represented by etha- } \\
\text { nol (step 1) }\end{array}$ & Lake & $39 \mathrm{~h}$ & 1.045 & n.a. & n.a. \\
\hline Propylene & Hexene-1 (step 2) & Lake & $87 \mathrm{~h}$ & 1.099 & Butene (step 3) & 1 \\
\hline Benzene & 3-Methyl-pentane (step 4) & Air & 28 days & 1.764 & Decene-1 (step 2) & 1 \\
\hline Toluene & $\begin{array}{l}\text { Oxygenates represented by etha- } \\
\text { nol (step 1) }\end{array}$ & Lake & $39 \mathrm{~h}$ & 1.045 & $\begin{array}{l}\text { Decene-1 (step 2), } \mathrm{C}_{7} \mathrm{H}_{14} \mathrm{O}_{x} \text {, } \\
\text { represented by Amyl Acetate } \\
\left(\mathrm{C}_{7} \mathrm{H}_{14} \mathrm{O}_{2}\right) \text { (step 4), di-heptyl } \\
\text { ether (step 5), (step 8) }\end{array}$ & 1 \\
\hline Xylenes $^{\mathrm{b}}$ & $\begin{array}{l}\text { Oxygenates represented by etha- } \\
\text { nol (step 1) }\end{array}$ & Lake & $39 \mathrm{~h}$ & 1.045 & $\begin{array}{l}\text { Decene-1 (step 2), } \mathrm{C}_{7} \mathrm{H}_{14} \mathrm{O}_{\mathrm{x}} \text {, } \\
\text { represented by Amyl Acetate } \\
\left(\mathrm{C}_{7} \mathrm{H}_{14} \mathrm{O}_{2}\right) \text { (step 4), di-heptyl } \\
\text { ether (step 5) }\end{array}$ & 1 \\
\hline Styrene & 3-Methyl-pentane (step 4) & Air & 28 days & 1.764 & Decene-1 (step 2) & 1 \\
\hline
\end{tabular}

The calculated SWwaste values are presented in Fig. 5

${ }^{\text {a }}$ Time required to reach $0.1 \%$ of initial volume of waste including the 1 year of waste generation (year)

${ }^{\mathrm{b}}$ Benzene formed during the disproportion reaction (step 8), which is a product and not waste 
Fig. 6 Sustainability indices of basic chemicals in a Czech Republic, b Hungary, c Poland, d Slovakia
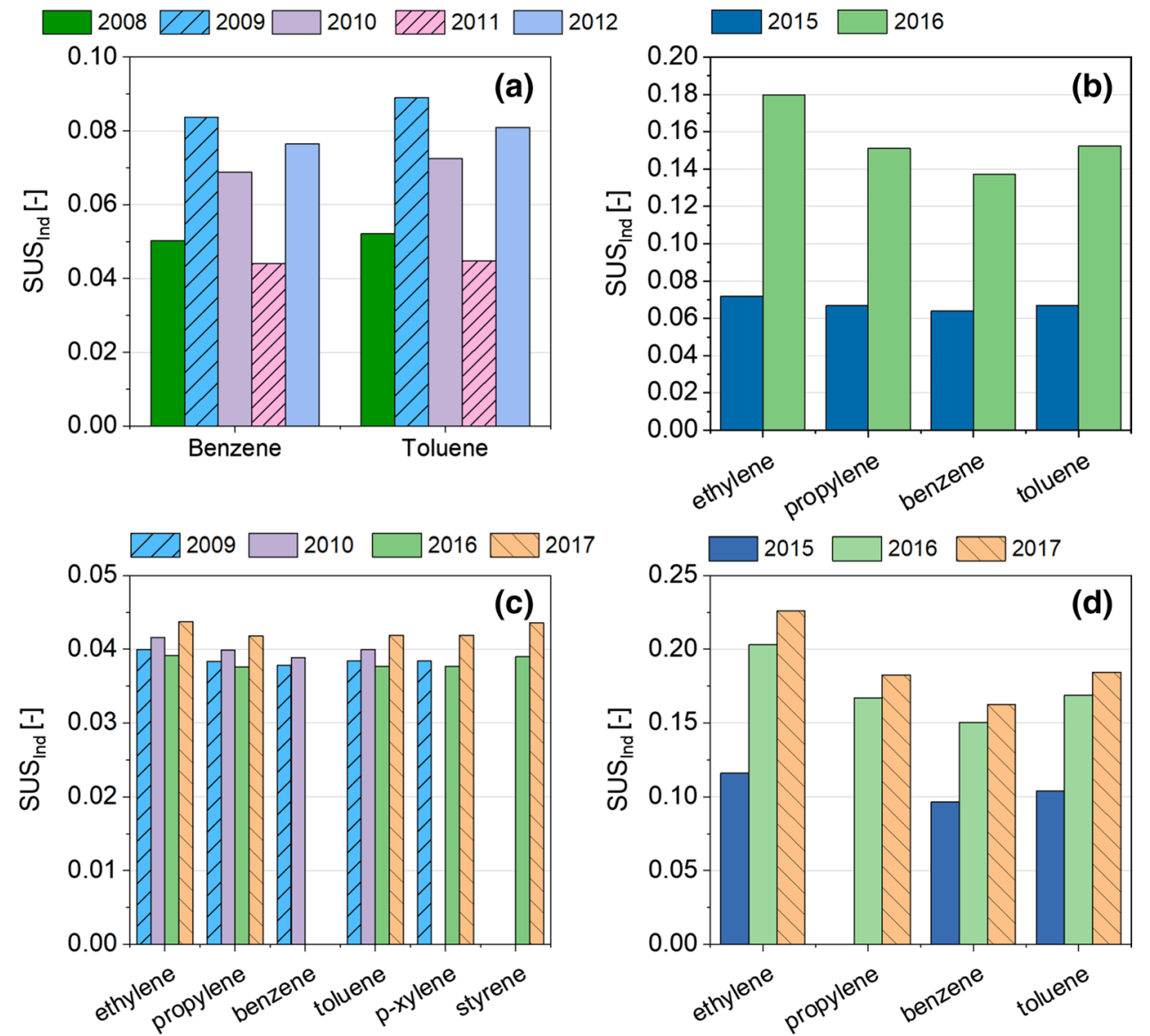

The same chemical production technology is assumed in all countries, consequently, $\mathrm{SV}_{\text {waste }}$ values are the same thus environmental sustainability is governed by the reproduction. It was also revealed that the same industrial-scale chemical technology, chemical reactions (moreover equipment) can be used for the synthesis of each chemical in all countries on the one hand; and due to the simplification of the waste formula (see Eq. 5), waste generation, waste treatment, and waste natural decomposition times influence the value of $\mathrm{SV}_{\text {waste }}$ on the other hand; consequently, $\mathrm{SV}_{\text {waste }}$ values of a chemical are the same in each country. It should be noted that the $\mathrm{SV}_{\text {waste }}$ values do not differ from data calculated for the USA and depends exclusively on the decomposition of the chemicals.

\section{Analysis of environmental sustainability: sustainability indicator}

According to the calculation methodology and Eq. 3, SUS ${ }_{\text {ind }}$ is governed by the smaller parameter, in our assessment always $\mathrm{SV}_{\text {rep }}$, because the same chemical production technologies having the same $\mathrm{SV}_{\text {waste }}$ values can be used in each country. Due to the limited amount of bioethanol and its proportional distribution between the chemicals the low $\mathrm{SV}_{\text {rep }}$

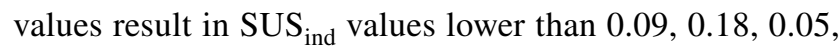
and 0.25 in Czech Republic, Hungary, Poland, and Slovakia, respectively (Fig. 6). If $\mathrm{SV}_{\text {rep }}$ is sustainable its value reaches or overcomes 1 , similarly to $\mathrm{SV}_{\text {waste }}$, consequently $\mathrm{SUS}_{\text {ind }}$ must be at least 0.5 or even higher to reach sustainability. Of the countries studied the ethylene production in 2017 in Slovakia shows the highest SUS $_{\text {ind }}$ value (0.226), but it is far below 0.5 .

In comparison with the data calculated for the USA in 2008 and 2014 (Horváth et al. 2017), the SUS ind $_{\text {values }}$ shows same order of magnitude verifying the fact that the sustainable production of these basic chemicals is not feasible at the current stage and primarily depends on the $\mathrm{SV}_{\text {rep }}$ values.

\section{Conclusions and outlook}

It was demonstrated that a transition from fossil resources to bioethanol as a raw material of the chemical industry could be viable but actually could not be realistic due to the limited amount of bioethanol. It was pointed out that industrial-scale technology exists that uses bioethanol with $100 \%$ conversion and $99 \%$ selectivity to produce ethylene. 
Ethylene then can be further used in well-known chemical processes to produce basic chemicals such as propylene, toluene, xylenes, styrene, and benzene. We have assessed the environmental sustainability of chemical industry in the Visegrad countries by using three ethanol equivalent-based sustainability metrics, namely the sustainability value of resource replacement, the sustainability value of the fate of waste, and sustainability indicator. It was revealed that the current bioethanol production in each country-in spite of the continuous increase in ethanol production-cannot cover the feedstock needs of the chemical industry, and the sustainability value of resource replacement determines the low value of the sustainability indicator. The same chemical technology can be used in Czech Republic, Hungary, Poland, and Slovakia - therefore-the sustainability values of the fate of waste of the selected chemicals are the same, thus strengthening our previous conclusion: i.e., environmental sustainability greatly depends on bioethanol production. The low values of $\mathrm{SV}_{\text {rep }}$ in each country could be increased when second-generation bioethanol would be added to the primary resources. It should be noted that although cellulosic ethanol production has been started in the V4-countries its volume is one order of magnitude lower than starch-based first-generation bioethanol (see further details on cellulosic ethanol provided by the European Technology and Innovation Platform (Cellulosic Ethanol 2020). Our assessment is simple one, but enlightened dual conclusions: (1) basic chemicals can be produced on bioethanol basis and the chemical industry may be switched to biomass basis instead of fossil fuels (2) the current bioethanol production is far below the industrial requirements and its volume has to be increased by one order of magnitude.

Acknowledgements Open access funding provided by Budapest University of Technology and Economics (BME). Edit Cséfalvay is grateful to the support of János Bolyai Research Scholarship of the Hungarian Academy of Sciences, and ÚNKP-18-4-BME-192 Project. The research reported in this paper has been supported by the National Research, Development and Innovation Fund (TUDFO/51757/2019ITM), Thematic Excellence Program. This work was funded by National Research, Development and Innovation Office under projects KH 129508 as well as Higher Education Excellence Program of the Ministry of Human Capacities in the frame of Biotechnology research area of Budapest University of Technology and Economics (BME FIKP-BIO).

Open Access This article is licensed under a Creative Commons Attribution 4.0 International License, which permits use, sharing, adaptation, distribution and reproduction in any medium or format, as long as you give appropriate credit to the original author(s) and the source, provide a link to the Creative Commons licence, and indicate if changes were made. The images or other third party material in this article are included in the article's Creative Commons licence, unless indicated otherwise in a credit line to the material. If material is not included in the article's Creative Commons licence and your intended use is not permitted by statutory regulation or exceeds the permitted use, you will need to obtain permission directly from the copyright holder. To view a copy of this licence, visit http://creativecommons.org/licenses/by/4.0/.

\section{References}

Budai I (2020) Hungary, landscape of the european chemical industry 2020. https://www.chemlandscape.cefic.org/wp-content/uploads/ pdfs/Hungary-65.pdf. Accessed 12 Apr 2020

CEFIC (2020) FACTS AND FIGURES of the European chemical industry. https://cefic.org/app/uploads/2019/01/The-EuropeanChemical-Industry-Facts-And-Figures-2020.pdf. Accessed 12 Apr 2020

Cellulosic Ethanol (2020) http://www.etipbioenergy.eu/value-chains/ products-end-use/products/cellulosic-ethanol. Accessed 14 Feb 2020

Chang F-C, Lin L-D, Ko C-H et al (2017) Life cycle assessment of bioethanol production from three feedstocks and two fermentation waste reutilization schemes. J Clean Prod 143:973-979. https:// doi.org/10.1016/j.jclepro.2016.12.024

Convay J (2020) U.S. production of high fructose corn syrup 20052016. https://www.statista.com/statistics/496475/high-fructosecorn-syrup-production-in-the-us/. Accessed 14 Feb 2020

Cséfalvay E, Horváth IT (2018) Sustainability assessment of renewable energy in the United States, Canada, the European Union, China, and the Russian Federation. ACS Sustain Chem Eng 6:8868-8874. https://doi.org/10.1021/acssuschemeng.8b01213

Cséfalvay E, Akien GR, Qi L, Horváth IT (2015) Definition and application of ethanol equivalent: sustainability performance metrics for biomass conversion to carbon-based fuels and chemicals. Catal Today 239:50-55. https://doi.org/10.1016/j.cattod.2014.02.006

Eurostat (2020) https://ec.europa.eu/eurostat/web/prodcom/data/datab ase?p_p_id=NavTreeportletprod_WAR_NavTreeportletprod_ INSTANCE_iSpjsGQt409q\&p_p_lifecycle=0\&p_p_state $=$ norma $1 \& p \_p \_m o d e=v i e w \& p \_p \_c o l \_i d=$ column-2\&p_p_col_count $=1$, excel files 2008-2017. Accessed 14 Feb 2020

Gallagher PW, Yee WC, Baumes HS (2016) 2015 Energy balance for the corn-ethanol industry. USDA, Washington

Guerrero AB, Muñoz E (2018) Life cycle assessment of second generation ethanol derived from banana agricultural waste: environmental impacts and energy balance. J Clean Prod 174:710-717. https ://doi.org/10.1016/j.jclepro.2017.10.298

Horváth IT, Cséfalvay E, Mika LT, Debreczeni M (2017) Sustainability metrics for biomass-based carbon chemicals. ACS Sustain Chem Eng 5:2734-2740. https://doi.org/10.1021/acssuschemeng.6b030 74

Jansen ML, van Gulik WM (2014) ScienceDirect towards large scale fermentative production of succinic acid. Curr Opin Biotechnol 30:190-197. https://doi.org/10.1016/j.copbio.2014.07.003

Knoema (2020a) https://knoema.com/atlas/Czech-Republic/topics/ Energy/Renewables/Fuel-ethanol-production. Accessed 14 Feb 2020

Knoema (2020b) https://knoema.com/atlas/Hungary/topics/Energy/ Renewables/Fuel-ethanol-production. Accessed 14 Feb 2020

Knoema (2020c) https://knoema.com/atlas/Poland/topics/Energy/ Renewables/Fuel-ethanol-production. Accessed 14 Feb 2020

Knoema (2020d) https://knoema.com/atlas/Slovakia/topics/Energy/ Renewables/Fuel-ethanol-production. Accessed 14 Feb 2020

Mamman AS, Lee J-M, Kim Y-C et al (2008) Furfural: hemicellulose/ xylosederived biochemical. Biofuels Bioprod Bioref 2:438-454. https://doi.org/10.1002/bbb.95

Mika LT, Cséfalvay E, Németh Á (2018) Catalytic conversion of carbohydrates to initial platform chemicals: chemistry and 
sustainability. Chem Rev 118:505-613. https://doi.org/10.1021/ acs.chemrev.7b00395

Murphy DJ, Hall CAS (2010) Year in review-EROI or energy return on (energy) invested. Wiley, New York

Nghiem N, Kleff S, Schwegmann S (2017) Succinic acid: technology development and commercialization. Fermentation 3:26. https:// doi.org/10.3390/fermentation3020026

Petersen GR (2004) Top value added chemicals from biomass: results of screening for potential candidates from sugars and synthesis Gas, vol 1. Pacific Northwest National Laboratory PNNL and the National Renewable Energy Laboratory NREL, Richland, pp 1-76

Pubchem (2020) Pubchem database. https://pubchem.ncbi.nlm.nih. gov/. Accessed 14 Feb 2020

Shapouri H, Gallagher PW, Nefstead Schwartz WR, Noe S, Conway R (2010) Energy balance for the corn-ethanol industry, USDA, 2008. Agricultural economic report number 846

Soucek I (2020) Czech Republic, landscape of the european chemical industry 2020. https://www.chemlandscape.cefic.org/wp-conte nt/uploads/pdfs/Czech-Republic-59.pdf. Accessed 12 Apr 2020
Surova S (2020) Slovakia, landscape of the European chemical industry 2020. https://www.chemlandscape.cefic.org/wp-content/uploads/ pdfs/Slovakia-76.pdf. Accessed 12 Apr 2020

Yang L, Lübeck M, Lübeck PS (2017) Aspergillus as a versatile cell factory for organic acid production. Fungal Biol Rev 31:33-49. https://doi.org/10.1016/j.fbr.2016.11.001

Zhao Y, Damgaard A, Liu S et al (2020) Bioethanol from corn stoverintegrated environmental impacts of alternative biotechnologies. Resour Conserv Recycl 155:104652. https://doi.org/10.1016/j. resconrec.2019.104652

Zielinski T (2020) Poland, landscape of the European chemical industry 2020. https://www.chemlandscape.cefic.org/wp-content/uploa ds/pdfs/Poland-72.pdf. Accessed 12 Apr 2020

Publisher's Note Springer Nature remains neutral with regard to jurisdictional claims in published maps and institutional affiliations. 